\title{
LAS NUEVAS POBLACIONES DE CARTAGENA DE INDIAS, 1774-1794
}

\author{
POR \\ MANUEL LUCENA GIRALDO \\ St. Antonv's College \\ Universidad de Oxford - CSIC
}

\section{INTRODUCCIÓN}

Entre 1764 y 1792, aproximadamente, transcurren los años en los que el denominado Reformismo Borbónico influyó en los destinos políticos de la América Española. Frente a la tradicional alianza de la corona con la burocracia, el clero y las élites regionales, el pujante Estado centralizador de los Borbones intentó imponer un nuevo modelo, ya experimentado parcialmente en la península, que propugnaba el recorte de las autonomías locales, la reforma fiscal y militar y la ejecución de proyectos de renovación productiva y especialización económica regional. Se trataba, en cierto modo, de revivir la pujanza de la España del siglo XVI, mediante un proyecto de modernización que lograra la edificación de un "Segundo Imperio" español en el Nuevo Mundo (1).

La nueva política gubernamental en América, con la extensión de las visitas a distintos territorios, el establecimiento de las intendencias, la gradual introducción del comercio libre y otras importantes medidas fue simultánea a modificaciones en la situación interna vinculadas al crecimiento de la población y la expansión minera, agropecuaria y comercial. Las transformacio-

SIGLAS UTILIZADAS:

AGI: Archivo General de Indias, Sevilla.

AHNC: Archivo Histórico Nacional de Colombia, Santa Fe de Bogotá.

Proyecto de Investigación PB91-0957; Investigador Principal, Francisco de Solano.

(1) Ver John Lync'H, El Siglo XVIII, Barcelona, Ed. Crítica, 1991, págs. 314 y ss. 
nes que caracterizaron el periodo resultaron de la conjunción de ambos grupos de factores (2).

Uno de los elementos menos estudiados dentro de la ideología de las Reformas Borbónicas es la actitud poblacionista. En un contexto en el que la ocupación física de continente americano había cobrado una importancia de la que antes carecía, llegando a convertirse en un factor fundamental de la política ultramarina española (3), la existencia de multitud de proyectos y algunas interesantes realizaciones ha recabado, por lo general, escaso interés de los historiadores (4). Los planes poblacionistas, además, se han explicado aislados de su contexto histórico, como si fueran el resultado de la actividad de personalidades iluminadas, un sistema para obstaculizar el contrabando en áreas conflictivas 0 , simplemente, en términos de política de poder, cuando solían llevar implícito un sentimiento agrarista que propugnaba el aumento de la riqueza y el bienestar general sobre la base del crecimiento de la población útilmente empleada, lindando en

(2) John LYNCH, Hispanoamérica, 1750-1850. Ensayos sobre la Sociedad y el Estado, Bogotá, Universidad Nacional, 1987, pág. 7.

(3) Ver Manuel Lucena GiRAldo, Laboratorio Tropical La Expedición de Limites al Orinoco, 1750-1767, Caracas, Monte Avila-CSIC, 1993, págs. 65 y ss.

(4) Una panorámica general del problema en Francisco de SolanO, "Ciudad y geoestrategia española en América durante el siglo XVIII", La América Española durante el siglo de las luces, Madrid, Ed. Cultura Hispánica-Quinto Centenario, 1988, págs. 37 y ss. y Ciudades Hispanoamericanas y Pueblos de Indios, Madrid, CSIC, 1990. Hay algunos estudios regionales como el de Gilbert DIN, The canary islanders of Lousiana, Baton Rouge-Londres, Lousiana State University Press, 1988 o trabajos sobre antecedentes de proyectos de población como el de Demetrio Ramos, "La exploración de San Julián en la costa patagónica y el marques de Valdelirios", Revista de Indias, $\mathrm{n}^{2}$ 49, Madrid, CSIC, 1952, págs. 497 y ss. En el caso de Chile se erigió una junta de poblaciones e incluso se confirió a Domingo Ortiz de Rozas el título de Conde de Poblaciones por su labor a mediados del siglo XVIII en el asentamiento de 513 familias en nueve fundaciones situadas en las provincias de Ytata, Maule, Malapilla, Quillota y Huasco. Ver Santiago LoRENzo y Rodolfo Urbina, La politica de poblaciones en Chile durante el siglo XVIII, Quillota, 1979. Para otros casos regionaless ver Jorge LuJÁn MUÑoz, "Fundación de villas de ladinos en Guatemala en el último tercio del siglo XVIII", Re'vista de Indias, no 145-146, Madrid, CSIC, págs. 51 y ss; Germán de GranI)A, "Origen, función y estructura de un pueblo de mulatos libres en el Paraguay del siglo XVIII" (San Agustín de la Emboscada), Revista de Indias, n 171, Madrid, 1983, págs. 229 y ss. y Fidel de Lejarza, Conquista espirintal del Nuevo Santander, Madrid, CSIC, 1957. Para el caso de Cuba véanse los estudios de Consuclo Naranjo Orovio, "Medio siglo de política poblacionista en Cuba, 1790-1840", IX Congreso Internacional de Historia de América, Sevilla, 1992, págs. 321-339; "Fomento y organización del territorio: un proyecto perdurable del Conde de Mopox y Jaruco", Cuba Ilesstrada, La Real Comisión de (stantanamo, 1796-1802. Madrid, 1991, págs. 53-75 y "Colons et Nouvelle's Ville's a Cuba, 1765-1802". (jeographie's, Colonisations, Descolonisations, XVe-XXe siecles. Burdeos, 1993. 
ocasiones con la utopía de la sociedad rural modelo (5). Por otra parte, el estudio de los proyectos de población se debe relacionar con el juego que se estableció entre las diversas fronteras regionales americanas y la frontera imperial, cuyo avance era dirigido desde la metrópoli. Entre ambas se dio una relación de oposiciones, neutralidades y beneficios mutuos, a causa de la cual, según cada caso, se opusieron, se equipararon o se superpusieron los distintos sistemas de control del espacio que pugnaban por imponerse unos a otros, formando un cuadro de una extraordinaria complejidad.

El caso de la Nueva Granada es ciertamente peculiar, y no solo por ser el único territorio americano en el que no se implantaron las intendencias (6). Su extraordinaria situación geográfica, con la pertenencia del istmo panameño y la posesión de costas tanto en el océano Atlántico como en el Pacífico, era de una gran importancia estratégica. De hecho, la continua amenaza británica y la existencia de territorios como la Guajira, el Darién o los Llanos desvinculados de la estructura imperial acabarían obligando a las autoridades peninsulares a llevar a cabo la definitiva refundación del Virreinato neogranadino en 1739 como medio para fortalecer su defensa.

Con la más importante producción de oro del continente, Nueva Granada tenía en Cartagena un puerto excelente y, a pesar de los sucesivos ataques, relativamente seguro, pero su estructura de comunicaciones era deficiente y su población, numerosa pero muy dispersa, era al decir del arzobispo-virrey Antonio Caballero y Góngora, "un monstruo indomable que a todo lo bueno se resiste» (7). Aunque la situación de la red urbana y, en general, de todo el poblamiento neogranadino fue una verdadera obsesión para los sucesivos virreyes, sería durante la segunda mitad del siglo, durante el apogeo de la etapa reformista, cuando se llevó a cabo el plan de asentamiento más importante de todos: el de las llamadas "Nuevas Poblaciones» de Cartagena de Indias.

(5) A este respecto ver el excelente libro de Vicente Llombart, Campomanes, economista y político de Carlos III, Madrid, Alianza Editorial, 1992, págs. 213 y ss.

(6) Con la excepción de la intendencia de Cuenca, en la Audiencia quiteña.

(7) Germán Colmenares Ed. Relaciones e informes de los gobernantes de la Nueva Granada, Tomo I, Bogotá, Banco Popular, 1989, pág. 411. Sobre el arzobispo-virrey Antonio Caballero y Góngora, ver J. M. PÉREZ AyAla, Antonio Caballero y Góngora, virrey y arzobispo de Santa Fe, 1723-1796, Bogotá, Imprenta Municipal, 1951. 
2. UN MODELO DE RETÓRICA OFICIAL: LA NOTKCIA INDIVIDU/AL DE LAS

POBLACIONES NUEVAMENTE FUNDADAS EN I.A PROVINCIA DE

CARTAGENA DE ANTONIO DE LA TORRE (1794)

La gobernación de Cartagena constituia, poco antes de la promulgación del Reglamento de Comercio Libre, un territorio relativamente próspero (8). En los alrededores de Mompós y Simití y en el golfo del Darién se cultivaba cacao, al igual que caña de azúcar, dedicada casi en su totalidad a la fabricación de aguardiente. Había labores de tabaco en el partido de Santo Tomás y las montañas de María, de algodón en diversos lugares, de maíz en el Sinú, Lorica y el Canal del Dique y de arroz en los palenques de San Basilio, el Dique y la costa de María (golfo de Morrosquillo). La sal se recogía en abundancia en la isla de Barú y la ciénaga de Tesca. De las haciendas situadas en los alrededores de la capital, cuyo abastecimiento era un importante negocio, se llevaban plátanos, yuca, name, miel, fríjoles, frutales y hortalizas. Por fin, en las sabanas de Corozal, Tierradentro y Mompós había hatos de ganado vacuno y caballar y en las haciendas de Barú y Bocachica se practicaba la cría de porcinos, al igual que en el interior de la ciudad amurallada. Alrededor de Cartagena se podían encontrar tejares, ladrilleras, carboneras y se cogía leña en abundancia.

La producción estaba organizada por medio de grandes haciendas, herencia de antiguas encomiendas, además de estancias y multitud de pequeñas "rozas de pan coger». Las primeras se manejaban principalmente con mano de obra esclava, aunque también mantenían arrendatarios y jornaleros. En las estancias

(8) No existe, que nosotros sepamos, una monografía general sobre la Nueva Granada en el siglo XVIII. A pesar de abordar un período ligeramente posterior, es imprescindible la consulta de Anthony McFarLane, "Comerciantes y monopolio en la Nueva Granada: el Consulado de Cartagena de Indias", Anuario Colombiano de Historia Social y de la Cultura, $\mathrm{n}^{2}$ 11, Bogotá, Universidad Nacional, 1983, págs. 43 y ss. Ver también José Antonio Ocampo, Ed. Historia económica de Colombia, Bogotá, Ed. S. XXI, 1987, págs. 13 y 49 y ss. Un estudio comparativo reciente en John R. FISHER, Alan C. KUETHE y Anthony McFARI.ANE Eds. Reform and insurrection in Bourbon New Granada and Peru, Baton Rouge \& Londres, Louisiana State University Press, 1990. Sobre cuestiones educativas ver el excelente Renán SILva, Saber, cultura y sociedad en el Nuevo Reino de Granada, siglos XVII-XVIII, Bogotá, Universidad Pedagógica, 1984. Sobre Cartagena y su provincia ver, entre otros, Eduardo Lemaitre, Historia General de Carlagena, T. II, Bogotá, Banco de la República, 1983; Orlando Fals Borda, Historia doble de la costa, 4 vols., Bogotá, Carlos Valencia Eds., 1979-1986; y el clásico libro de Enrique Marco DORTA, Cartagena de Indias, Puerto y Plaza Fuerte, Bogotá, Fondo Cultural Cafetero, 1988. 
había pocos esclavos y las rozas eran, cultivadas por sus dueños, la gran mavoría campesinos pobres (9). Los comerciantes más poderosos del Virreinato, grandes hacendados, funcionarios, militares, religiosos y cabildantes componian los grupos más poderosos de una sociedad multiracial y compleja, formada en sus estratos inferiores por quienes desempeñaban oficios artesanales, carpinteros y traficantes, polizones y desertores, pícaros y contrabandistas, un considerable número de esclavos domésticos y de hacienda y algunos indios. Una estadística de la población de Cartagena - exceptuado el partido de Mompós- que fue enviada al virrey en 1778 señala que la ciudad contaba con 7.346 habitantes, de los cuales los eclesiásticos eran el 3,3\%, los vecinos el $36,8 \%$, sus familias componían el $25,1 \%$ y eran esclavos el $34,6 \%$ restante. En cuanto a la provincia, incluyendo los datos de la capital, contaba con 68.447 habitantes, divididos en un $0,4 \%$ de eclesiásticos, eran vecinos un $25,2 \%$, sus familias componían el $41,2 \%$, los indios un 22,5\% y los esclavos un 10,4\%, como se puede observar en el cuadro y gráficos siguientes (10).

Una de las características permanentes de la gobernación de Cartagena fue la irregularidad de su poblamiento, reflejo inequívoco de su inestabilidad social (11). Entre la fuerza militar y el pacto con los grupos marginales - un último recurso dirigido a evitar un conflicto de consecuencias siempre peligrosas- las autoridades coloniales podían tomar todo tipo de resoluciones. A este respecto, no debemos olvidar que, en el contexto regional, la importancia de los palenques de negros llegó a recibir ocasionalmente una sanción institucional, como en el caso del de San Basilio, en la sierra de María, que pactó en 1713 con el obispo

(9) Adolfo R. Meisel, "Esclavitud, mestizaje y haciendas en la provincia de Cartagena, 1533-1851", Desarrollo y Sociedad, n 4, Bogotá, CEDE-Uniandes, págs. 255-260.

(10) El cuadro está basado en el "Resumen General de Vecinos y almas de la provincia de Cartagena exceptuado el partido de Mompós" que envió el gobernador Juan Pimienta al virrey; Cartagena, 11 de enero de 1778, AHNC, Milicias y Marina, Tomo 141. El número de almas menos el de vecinos y eclesiásticos da el número de miembros de las familias de los propios vecinos. La ciudad de Cartagena habría tenido en 1772, según la Noticia Historial del obispo Peredo -un poco anterior a nuestros datos- 11.379 habitantes: un 81 \% de ellos eran blancos y mestizos, el resto negros. La provincia contaría con 67.367 habitantes; Diego de Perfodo, "Noticia Historial de la Provincia de Cartagena de Indias (1772)", Anuario Colombiano de Historia Social y de la Cultura, no 6-7, Bogotá, Universidad Nacional, 1972.

(11) Ver María del Carmen Borrago Pla, Palenques de negros cimarrones e'n Cartagena de Indias a fine's del siglo XVII, Sevilla, Escuela de Estudios Hispanoamericanos, 1972. 


\section{POBLACHON DE LA PRONWCAA DE CARTAGENA 1778}

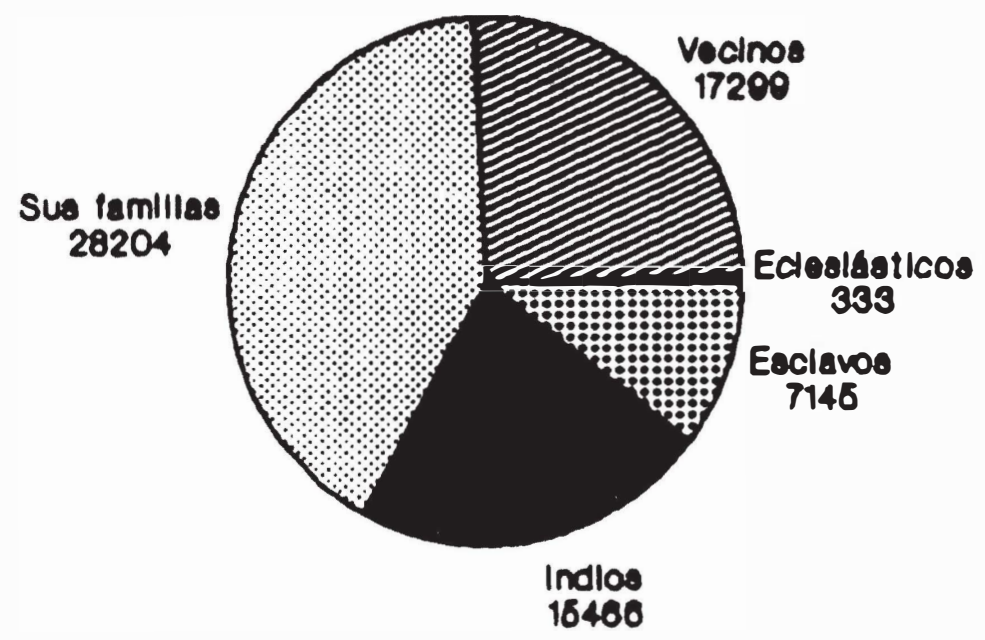

\section{POBLACION DE LA CIUDAD DE CARTAGENA 1778}

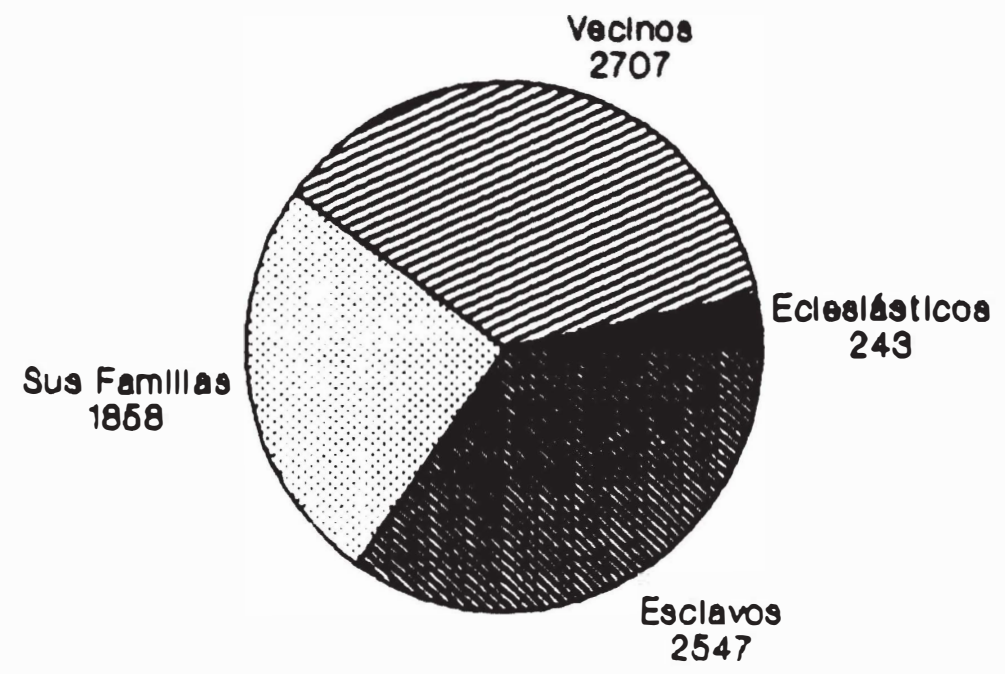

R. I., 1993, n 199 
Casiani obteniendo la propiedad de sus tierras y el respeto a su libertad y organización política a cambio de no aceptar más esclavos fugados y deponer las armas.

El 12 de agosto de 1774 el gobernador de Cartagena Juan Pimienta ordenó al capitán Antonio de la Torre Miranda pasar a la cercana isla de Barú con el fin de practicar un reconocimiento, examinar la calidad de los terrenos y establecer poblaciones y parroquias (12). De acuerdo con la visión historiográfica clásica sobre el particular, Antonio de la Torre habría sido un represen-

\section{RESUMEN GENERAL DE VECINOS Y ALMAS DE LA PROVINCIA DE CARTAGENA EXCEPTUADO EL PARTIDO DE MOMPOS (1778)}

\begin{tabular}{|c|c|c|c|c|c|c|}
\hline PARTIDOS & ECLS. & VECINOS & $\mathrm{N}^{2}$ ALMAS & INDIOS & ESCL. & TOTAL \\
\hline \multicolumn{7}{|l|}{ Cartagena } \\
\hline Extramuros & 15 & 117 & 451 & & 299 & 750 \\
\hline Bocachica & 1 & 130 & 431 & & 106 & 537 \\
\hline Barú & 1 & .103 & 436 & & 70 & 506 \\
\hline Mahates & 12 & 1.997 & 5.197 & 752 & 1.213 & 7.162 \\
\hline Barranca & 3 & 163 & 588 & 230 & 78 & 896 \\
\hline Tierra & & & & & & \\
\hline Adentro & 21 & 3.709 & 12.933 & 3.356 & 578 & 16.867 \\
\hline $\begin{array}{l}\text { Tolú y } \\
\text { sabanas }\end{array}$ & 37 & 8.373 & 20.988 & 11.128 & 1.646 & 33.762 \\
\hline TOTAL & 333 & 17.299 & 45.836 & 15.466 & 7.145 & 68.447 \\
\hline
\end{tabular}

(12) Antonio de la Torre Miranda nació en Villada (Palencia) hacia 1735. A partir de los 18 años prestó servicios en la Armada y el Ejército. Fue comandante de las partidas de reclutas en Madrid, Palencia, León, Ríoseco y Santiago. Pasó a Nueva Granada como teniente en 1772, participando en la formación de las milicias de Cartagena de Indias -en las que fue ayudante de las compañías de pardos- en la fundación de poblaciones en Cartagena y el Sinú y en la exploración del Atrato (1779). En 1782, comisionado por el arzobispo-virrey Caballero y Góngora, exploró la ruta de los ríos Meta y Orinoco hasta Angostura, capital de la Guayana y se ocupó de los problemas relacionados con la población del Nuevo Reino. Sobre este viaje, ver "Diario y relación del viaje hecho por el capitán D. Antonio de la Torre por diversas partes del Virreinato de Nueva Granada (1782. 1783)", Historiografia y Bibliografia Americanistas, Vol. XVII, $\mathrm{n}^{Q} 1-2$, Sevilla, Escuela de Estudios Hispanoamericanos, págs. 53 y ss. y Carlota Bustos, "Viaje al Orinoco en 1782", Boletín de la Sociedad Geográfica de Colombia, Vol. XXXVI, n 100, Bogotá, 1968. 
tante aventajado de los pobladores pactistas (13). Según indica la referencia más o menos habitual, tras abrir multitud de caminos y hacer navegables caños, ciénagas y ríos "con utilidad del público y la haciendan, el capitán poblador estableció en el curso de seis expediciones entre 1774 y 1778 un total de 44 fundaciones, reuniendo casi 42.000 habitantes. El contingente de nuevos pobladores se formó agrupando la población dispersa que vivía en los montes, descendientes de tropa y marinería, desertores, polizones, esclavos huidos, cimarronas, prófugos, criminales escapados de los presidios y cárceles e indios, que mezclados habían dado lugar a "una abundante casta de zambos, mestizos, y otros matices dificiles de determinan (14). Su vivienda habitual habían sido las rancherías diseminadas en espesos bosques, ciénagas y caños, sin orden, trabajo ni vestidos "de que no necesitaban por no tener frío ni vergüenza» (15). Con la llegada de Antonio de la Torre, que sólo habría contado para llevar a cabo su meritoria empresa con la ayuda de un criado, su sueldo de 32 pesos y algunos soldados, la peligrosa población dispersa de la provincia cartagenera habría sido milagrosamente reducida a policía civil, apren-

En 1783 preparó los proyectos de fundación en el Darién y al año siguiente reconoció los caminos del valle de Fusagasugá y sus inmediaciones para mejorar el abasto de Santa Fe de Bogotá, ocasión en la cual también hizo varias recolecciones de quina destinadas al sabio José Celestino Mutis. Tras participar desde ese año en el intento de asentamiento en el Darién y Calidonia -que tuvo que abandonar por su mal estado de salud- fue nombrado gobernador de las fortalezas de Bocachica, recibiendo en 1786 permiso para volver a España. Tras servir un tiempo en Zamora, pasó al puerto de Santa María (Cádiz), donde residia en 1794. Murió en la citada localidad el 6 de febrero de 1805 . Recientemente ha aparecido una biografía de Antonio de la Torre: Pilar MORENO DE Angel, Antonio de la Torre y Miranda, Viajero y Poblador, Bogotá, Ed. Planeta, 1993; agradecemos al Dr. Eduardo Posada que nos haya facilitado su consulta, que nos ha resultado muy esclarecedora. Sobre los militares y el ejército en Nueva Granada en este período ver Juan MARChEnA FERnÁndez, La institución militar en Cartagena de Indias, 1700-1810, Sevilla, Escuela de Estudios Hispanoamericanos, 1982 y Allan J. KUETHE, Military reform and society in New Granada, 1773-1808, Gainesville, University of Florida, 1978, especialmente págs. 130 y ss.

(13) En esta línea se pueden consultar desde el clásico José Manuel Groot, Historia eclesiástica y civil de la Nueva Granada, T. II, Bogotá, Ed. ABC, 1953, págs 289 y ss. hasta los recientes Eduardo LemaITRE, [8], págs. 334 y ss. y M. ${ }^{a}$ del Carmen Borrego Pla, "Las 'Nuevas Poblaciones' de Carlos III y Cartagena de Indias: la figura de Antonio de la Torre", Europa e Iberoamérica. Cinco siglos de intercambios, Vol. I, Sevilla, AHII.A et al., 1992, págs. 55 y ss. Este punto de vista se ha limitado a reiterar lo consignado por el propio Antonio de la Torre en su publicación, sin realizar crítica alguna a la información por el expuesta. El reciente libro de Pilar MORENO DE ANGFI., [12], aunque lo comparte, contiene algunas notables aportaciones.

(14) José Manuel Groot, [13], pág. 290.

(15) Ibid. 
diendo posteriormente las labores de la agricultura, la cría de ganado y diversas manufacturas, mientras las mujeres aprendían labores textiles y cestería. Por fin, la emulación de la vida civilizada habría producido el deseado efecto multiplicador, por lo que el ejemplo se habría divulgado por toda la región, convertida así en una versión tropical del proyecto poblacionista ejecutado por Pablo de Olavide con el patrocinio del Conde de Campomanes (16).

Resulta extraordinario que esta versión del proceso de asentamiento de las Nuevas Poblaciones, debida a la pluma del propio Antonio de la Torre, no haya sido sometida hasta el momento a una crítica adecuada. La explicación, siquiera parcial, podría ser que la única fuente disponible sobre las Nuevas Poblaciones ha sido la Noticia Individual de las poblaciones nuevamente fundadas en la provincia de Cartagena, que aquél publicó en 1794 para apoyar la consecución de diversas recompensas (17). La notable habilidad retórica de Antonio de la Torre se hace patente cuando intentamos definir la naturaleza del escrito, que reúne en una sola pieza un elaborado diario de viaje, una relación de méritos y servicios, una relación geográfica y diversos documentos aprobatorios de su conducta, vinculando la información sobre el territorio con la narración encubierta de su propia peripecia personal, el triunfo de la razón de Estado con la consecución de sus

(16) Ver [5], págs. 209 y ss., así como Cayetano AlcázAR, Las colonias alemanas de Sierra Morena, Madrid, 1930; Manuel CAPEL, La Carolina, capital de las Nuevas Poblaciones, Jaén, 1970; Manuel Martín Rodríguez, Pensamiento económico español sobre la población, Madrid, 1984; José María SuÁrez Gallego Ed. Real Cédula de S.M. y señores del Consejo que contiene la instrucción y fuero de población que se debe observar en las que se formen de nuevo en la Sierra Morena con naturales y extranjeros católicos (Madrid, 1767) (Facsímil), La Carolina, 1986; Miguel Avilés y Guillermo Sena Eds. Carlos III y las Nuevas Poblaciones, 3 vols., Córdoba, Universidad de Córdoba et al., 1988 y Vicente Palacio ATARD, Las Nuevas Poblaciones andaluzas de Carlos III. Los españoles de la ilustración, Córdoba, 1989.

(17) Hemos consultado la "Noticia Individual de las poblaciones nuevamente fundadas en la provincia de Cartagena" (1794), de Antonio de la Torre en una copia manuscrita depositada en la RAH Colección Muñoz, 9/4.104; las citas posteriores tienen esta procedencia. Fue publicada por primera vez por su autor en la Imprenta de Luis Luque de Leiva del puerto de Santa María (Cádiz) en 1794, y posteriormente por José P. Urueta, Documentos para la historia de Cartagena, T. VII, Cartagena, Imprenta Araújo, 1891, págs. 44 y ss. y en el Boletín Historial, n" 49, 50 y 51, Cartagena, Academia de la Historia de Cartagena de Indias, 1926. Subre ejemplares depositados en otras bibliotecas y archivos ver María del Carmen Borre(io Pla, [13], págs. 56 y Pilar Moreno de ANGili, [12], pág. 266. Antonio de la Torre pretendía que le recompensaran con cuatro títulos de Castilla, de los cuales vendería tres en su beneficio, petición que le fue denegada. Por este procedimiento se había financiado la fundación de diez villas en Chile cutre 1735 : 1745; ver Francisco de Sol.ANO, [4], pág. 43. 
recompensas. Antonio de la Torre avanzó así en la creación de un antimodelo, se salió de las categorias establecidas y, sensible a la moda literaria y política del momento, reelaboró en función de sus intereses el patrón burocrático comúnmente aceptado, poniéndolo al servicio de sus fines particulares.

Por tanto, la Noticia Individual resultó ser un ejercicio dialéctico construido con el propósito de demostrar que el proyecto cartagenero era una benéfica emulación de las Nuevas Poblaciones peninsulares. Antonio de la Torre comenzó el escrito haciendo una manifestación de fe en los instrumentos oficiales del progreso ilustrado:

Generalmente está admitida como una de las máximas interesantes al Estado el aumentar la población, el facilitar comunicación, correspondencia, tráfico interior y exterior por agua y tierra con las demás provincias o reinos, el fomentar la agricultura, la industria y la mineralogía, que son verdaderamente los principios sobre los que se establece la riqueza, la opulencia y la felicidad de los reinos (18).

Si hay poca originalidad en este punto, su posición en la llamada "polémica del Nuevo Mundo" es igualmente convencional (19). Según indica poco después, los americanos se han dado a una "delincuente pereza" por la prodigalidad de la naturaleza, ya que con el clima cálido "desmayan las fuerzas y se desecha por molestoso cualquiera abrigo, y como la soledad ofrece menos rubor y más desahogo, asi hombres como mujeres no acostumbran a cubrir más de sus cuerpos que aquellas partes que de justicia y necesidad pide la racionalidad». Tal situación ha sido remediada en lo posible gracias a su cruzada personal, en la que ha sido apoyado por los sucesivos virreyes, implantando el pasto espiritual y la justicia y luchando contra el trato ilícito y los fraudes a la Real Hacienda. De esta manera, gentes que aborrecían la sociedad han pasado a formar pueblos y gracias al reparto de tierras para ejidos y labores adelantan el cultivo de plátanos, maíz, arroz, frijoles y otros productos y la cría de ganado mayor y menor. Las mujeres han aprendido a tejer lienzos, mantelerías y hamacas, labores de aguja y cestería. Por fin, los peligros que acechaban al comercio han desaparecido y la provincia se encuentra en el

(18) [17].

(19) Sobre este asunto ver el insustituible Antonello GERBI, La disputa del Nuevo Mundo. Historia de una polémica, 1750-1900, México, FCE, 1982. 
camino del progreso ilustrado. Si atendemos a la información aportada por la Noticia Individual, la magnitud del proceso poblacional realizado por Antonio de la Torre habría sido extraordinaria, como se puede observar en el siguiente cuadro, en el que también señalamos las actividades económicas de los nuevos pueblos (20).

POBLACIONES FUNDADAS EN CARTAGENA DE INDIAS POR ANTONIO DE LA TORRE

\begin{tabular}{|c|c|c|c|}
\hline $\begin{array}{c}\text { I } \\
\text { PUEBLOS }\end{array}$ & $\begin{array}{c}\text { II } \\
\text { VECINOS }\end{array}$ & $\begin{array}{c}\text { III } \\
\text { HABITANTES }\end{array}$ & $\begin{array}{c}\text { IV } \\
\text { ACTIVIDADES } \\
\text { ECONOMICAS }\end{array}$ \\
\hline 1. Ternera & 50 & 230 & $1,2,3,4,5$ \\
\hline 2. San Juan de Timiriguaco & 60 & 258 & 5,14 \\
\hline 3. Arjona & 250 & 2.000 & $5,6,14$ \\
\hline 4. Pasacaballos & 72 & 258 & 7,14 \\
\hline 5. Santa Ana & 119 & 640 & $\begin{array}{l}8,5,9,10,11, \\
12,14\end{array}$ \\
\hline 6. San José de Rocha & 120 & 630 & $5,12,13,14,2,3$ \\
\hline 7. San José de Jolojolo & 80 & 360 & 6,10 \\
\hline 8. Santa Rosa de Flamenco & 60 & 302 & 6,10 \\
\hline 9. Gambote & 20 & & \\
\hline 10. San Cayetano & 80 & 310 & $2,3,5,6$ \\
\hline 11. San Juan Nepomuceno & 120 & 758 & $2,3,5,6$ \\
\hline 12. San Jacinto & 82 & 447 & $2,3,5,6$ \\
\hline 13. Nuestra Señora del Carmen & 90 & 694 & $2,3,5,6$ \\
\hline 14. San Francisco de Asís & 78 & 448 & $2,3,5,6$ \\
\hline 15. San Agustín de Playa Blanca & 19 & 73 & 13 \\
\hline 16. San José de Pileta & 473 & 3.055 & $15,16,18,6$ \\
\hline 17. San Luis de Since & 330 & 1.580 & \\
\hline 18. Santo Tomás Cantuariense & 19 & 105 & 5,18 \\
\hline 19. Cascajar & 131 & 555 & \\
\hline 20. Tacamocho & 189 & 955 & 14 \\
\hline 21. Tacaloa & 119 & 561 & \\
\hline 22. Nuestra Señora de Magangué & 287 & 1.415 & 14 \\
\hline 23. San Sebastián de Madrid & 99 & 593 & $5,12,15$ \\
\hline 24. El Retiro & 197 & 1.229 & $5,12,15$ \\
\hline 25. Tacasaluma & 199 & 596 & $5,12,15$ \\
\hline
\end{tabular}

(20) Elaborado a partir de la Noticia Individual, [17]. 


\begin{tabular}{|c|c|c|c|}
\hline $\begin{array}{c}\text { I } \\
\text { PUEBLOS }\end{array}$ & $\begin{array}{c}\text { II } \\
\text { VECINOS }\end{array}$ & $\begin{array}{c}\text { III } \\
\text { HABITANTES }\end{array}$ & $\begin{array}{c}\text { IV } \\
\text { ACTIVIDADES } \\
\text { ECONOMICAS }\end{array}$ \\
\hline 26. Santiago & 89 & 378 & $5,12,15$ \\
\hline 27. San Benitu Abad & 299 & 1.368 & 18,5 \\
\hline 28. San Cristóbal & 65 & 325 & \\
\hline 29. San Benitu de Torobe & 168 & 879 & 6 \\
\hline 30. Santero & 98 & 488 & \\
\hline 31. Sincelejo & 325 & 2.855 & \\
\hline 32. San Rafael de Chimú & 300 & 1.847 & 5 \\
\hline 33. San Juan de Sahagún & 207 & 1.057 & 5 \\
\hline 34. San Pedro Apóstol de Pinchoroy & 95 & 508 & 5 \\
\hline 35. San Antonio Abad & 140 & 677 & 5 \\
\hline 36. San Bernardo Abad & 299 & 1.368 & $14,5,19,20,18$ \\
\hline 37. Santa Cruz de Lorica & 858 & 4.358 & \\
\hline 38. San Pelayo & 276 & 1.475 & $14,5,18,20$ \\
\hline 39. Purísima Concepción & 306 & 1.417 & \\
\hline 40. San Antonio de Momil & 208 & 1.778 & \\
\hline 41. San Emigdio & 115 & 595 & \\
\hline 42. San Antonio de Ciénaga del Oro & 151 & 824 & 21 \\
\hline 43. San Carlos & 108 & 408 & 5,18 \\
\hline 44. San Jerónimo de Buenavista & 170 & 854 & 5 \\
\hline TOTAL & 7.620 & 41.511 & \\
\hline
\end{tabular}

IV. Actividades económicas: explicación de los números

1. Obrajes bastos.

2. Ganado de cerda.

3. Cría de aves domésticas.

4. Fábrica de carbón.

5. Labranzas de subsistencia.

6. Labranzas para la venta.

7. Guarnición militar.

8. Salinas.

9. Manantial de agua dulce.

10. Fábrica de cazabe.

11. Fábrica de cal.
12. Pesca.

13. Provisión de bogas o remeros.

14. Provisión de bastimentos o alojamiento.

15. Fábrica de aguardiente.

16. Manufacturas, sin especificar.

17. Obraje fino.

18. Ganado en general.

19. Fábrica de embarcaciones.

20. Corte de maderas.

21. Oro de Aluvión.

A pesar de la falta de datos cualitativos, según la Noticia Individual el proceso fundacional habría abarcado la isla de Barú, las sabanas y montañas de María, el Canal del Dique y el Sinú, con la agrupación de 41.511 habitantes en 44 pucblos y 22 
parroquias (21). El total de vecinos reunidos fue de 7.620 , por lo que el promedio resultante de miembros de las unidades familiares es de 5,44. Por otra parte, a pesar del gran número de nuevos establecimientos, emerge la imagen de una población muy agrupada. Aunque hay treinta localidades de menos de 1.000 habitantes, las otras catorce, Arjona, San José de Pileta, San Luis de Since, Nuestra Señora de Magangué, Retiro, San Benito Abad, Sincelejo, San Rafael de Chimú, San Juan de Sahagún, San Bernardo Abad, Santa Cruz de Lorica, San Pelayo, Purísima Concepción y San Antonio de Momil sobrepasan esta cifra, reuniendo 26.802 habitantes, el $64 \%$ de la población. Ahora bien, ¿Es posible buscar una visión alternativa del proceso fundacional? ¿Correspondió con la realidad la idílica imagen oficial de las Nuevas Poblaciones cartageneras transmitida por la Noticia Individual de 1794?

\section{LA NATURALEZA DEL PROCESO POBLACIONISTA}

A la vista de los datos expuestos, resulta fácil concluir, como pretendía Antonio de la Torre, que las poblaciones nuevamente fundadas en la provincia de Cartagena surgieron por el «efecto de demostración" de las Nuevas Poblaciones peninsulares (22). Sin embargo, la existencia de un Diario manuscrito suyo que narra el proceso poblacionista en una fase vital, desde su inicio hasta febrero de 1776, nos permite adquirir una imagen más real y cotidiana, menos oficialista, de los métodos, las vacilaciones, los logros y los fracasos del proceso poblador cartagenero (23).

(21) Antonio de la Torre indica en la Noticia Individual que fundó 43 pueblos, pero menciona 44. No hay datos sobre Gambote. Es imprescindible la consulta dé Pilar MORENO DE ANGEL, [12], Cap. IV, págs. 63 y ss.; indica que en la actualidad perduran 40 de los 43 pueblos. Sobre las diferentes localizaciones, ver Eugenio J. Gómez, Diccionario Geográfico de Colombia, Bogotá, Banco de la República, 1953.

(22) Ver Ramón GuTIÉRRe., Arquitectura y urbanismo en Iberoamérica, Madrid, Ed. Cátedra, 1983, pág. 221. En diferentés pasajes de la Noticia Individual Antonio de la Torre alude a la fundación de La Carlota, Luisiana y Carolina, la apertura de caminos a la manera de los de Sierra Morena, los regadios y canales de Manzanares y Murcia, etc...

(23) "Diario hecho por D. Antonio de la Torre de un viaje hecho en la provincia de Cartagena para establecer nuevas poblaciones" (agosto de 1774 a lebrero de 1776), Real. Jardín Botánico, Colección Mulis, 55 (Signalura antigua). Las referencias siguientes pertenecen a este escrito, salvo indicación en contrario. Agradecemos al Dr: Miguel Angel Puig-Samper, del Centro de Estudios Históricos del CSIC, que nos haya dado a conocer este importante documento. Hay un interesante mapa del prepio Antonio de la Torre, fechado en Cartagena el $13 \mathrm{de}$ junio de 1778, que complementa el diario y la Noticia Individual, depositado en el

R. I., 1993, n"199 
Según refiere el mencionado diario, en agosto de 1774 Antonio de la Torre pasó a la isla de Barú, donde tomó contacto con el problema fundacional. Lo primero que salta a la luz es que en ese momento el capitán poblador carecía tanto de un modelo urbanizador como de una metodología para asentar poblaciones, ya que su preocupación básica era militar, había que congregar a los isleños para evitar el «descubierto en que se hallaba dicho terrenon poniendo en peligro la plaza en caso de una invasión como las que periódicamente experimentaba Cartagena. El empirismo más absoluto presidió toda su labor hasta que el Diario se interrumpe, cuando ya ha asentado las nuevas poblaciones en Barú, el Canal del Dique y las montañas de María (24). Según su propio testimonio, al llegar a la isla sólo había encontrado algunos esclavos haciendo cal para "varios sujetos de Cartagena" y varios arrendatarios libres que cultivaban maíz, yuca y sandias. Tras reconocer el lugar, exploró el terreno en busca de un buen paraje para fundar y regresó a la ciudad, donde informó a las autoridades de la importancia de congregar a los pobladores de la isla. En octubre del mismo año se le ordenó establecerlos en el sitio de Santa Ana, para lo que contaría con la ayuda de un contingente de soldados del regimiento de granaderos. De nuevo en la isla, Antonio de la Torre convocó a todos sus habitantes, les empadronó y les comunicó el decreto del gobernador conminándoles a trasladar sus casas al lugar que había señalado, "con cuyo motivo les delineé el terreno y señalé a cada uno de ellos el solar que le correspondía». A continuación, pasó a Tierra Firme, exploró las ciénagas y caños de Matuma y el Canal del Dique y repitió el mismo proceso: orden de agrupación, empadronamiento, señalamiento del lugar donde debían construir nuevas casas y repartimiento de solares. La situación empeora progresivamente desde febrero de 1775, cuando el capitán poblador regresa a Barú y descubre que sus habitantes no han cumplido sus órdenes. Da entonces la orden de reunir por segunda vez a los isleños y les hace limpiar de nuevo el terreno de la futura población, mandándoles establecer allí sus casas e intentando convencerles, con las mejores palabras, de las ventajas de vivir en sociedad. Calles, solares, cuartel y cárcel son delineados otra vez. En Tierra Firme tiene lugar idéntico proceso, mientras aparecen diversas

Servicio Histórico Militar (Madrid), con signatura A.J.7 CA. $n^{0}$ 6. Fue publicado en Cartografía y Relaciones Históricas de Ultramar, T. V, Colombia-PanamáVenezuela, Madrid, Ministerio de Defensa, 1980, $n^{0} 7$.

(24) El Diario no recoge las fundaciones en el Sinú. 
formas de resistencia entre las que destaca por su importancia la difusión de rumores que indicaban ser "contra la voluntad de Su Majestad reunirlos a población".

De regreso en Barú, Antonio de la Torre se da cuenta de que en cuanto ha abandonado la isla se han detenido los trabajos de asentamiento en la nueva fundación de Santa Ana y los isleños se han "arrochelado" de nuevo. Comienza entonces una verdadera escalada de la tensión, en la que aquel emprende una cruzada fundacional con métodos cada vez más radicales, empeñado en enseñar a los habitantes dispersos "cómo padecian careciendo en aquellos destierros de todo lo que es apetecible a la vida humana". En marzo de 1775 ordena derribar las casas dispersas de los destinados a fundarse en San José de Rocha, con el objeto de aprovechar los materiales, por lo general maderas, palmas y bejucos para clavazón. En Santa Ana, donde seguían sin adelantar la fundación, les conmina a cumplir sus órdenes "para evitarles perjuicio, a ver si separaban de si aquel horror que tenian a la sociedad, pues punto menos que caribes estaban viviendo». Esta táctica de derribo de las casas dispersas se repite en las ciénagas de Barú, pero sin duda el paso a una definitiva política de fuerza tiene su manifestación más evidente en el nombramiento de cabos de justicia o capitanes voluntarios en cada sitio, con la misión específica de vigilar el estricto cumplimiento de sus órdenes y evitar la huida de la población a sus antiguas moradas.

El paso de Antonio de la Torre por el antiguo palenque de San Basilio es especialmente interesante, porque describe, aunque someramente, el asentamiento preexistente. Allí los habitantes tenían sus casas

colocadas a montón, sin orden de calles ni plaza, próximas a la iglesia y tan reducidas y mal hechas que casi no dan abrigo, y con mucha incomodidad caben en ellas las familias. Ninguna tiene puertas, ni ellos para su descanso tienen estera, cuero, tabla, ni otra cosa que algunos un bahareque de vástagos de palma, y otra especie de varas que mas bien se puede apropiar para potro de tormento que para descanso de cama.

Tras señalarles un lugar para la nueva fundación con sitio para aguada y montes de labor, Antonio de la Torre regresó a Santa Ana de Barú, descubriendo que sus pobladores habían huido por cuarta vez. Tomó entonces una drástica decisión:

Les hice quemar las cancheras [lugares dispersos de residen- 
cia] para quitarles aquel abrigo en que vivian internados en los montes y la esperanza de volverse a arrochelar, oprimiendo y amenazando a algunos para que escarmentasen los demás, pues habia varias familias que al abrigo de un árbol estaban con tanta satisfacción con ocho o diez hijos como uno pudiera estar en un palacio muy resguardado.

Esta táctica se repite donde la resistencia de los pobladores la hace necesaria, como en Timiriguaco, aunque también aplica la política opuesta, ya que en San Benito Abad llega a permitir que el cabildo elija el sitio del nuevo pueblo. Por fin, en Sincelejo se produce una sublevación contra el capitán voluntario, por lo que procede a hacer diversos arrestos entre los cabecillas y castiga públicamente varios delitos. En Pileta, cuyos pobladores rechazaban agruparse en el nuevo lugar del Corozal, le conminan a aceptar su petición ya que "cuando no fuese por bien lo haría por mal, que era inspiración divina [permanecer alli] por no desamparar al Santísimo Cristo de aquella iglesian. Los granaderos que lo acompañaban arrestan entonces 28 hombres, derriban las casas y a modo de colofón, se establece una fábrica de aguardiente sustituyendo a las ilegales que existían con anterioridad.

A medida que la concentración de pobladores se va haciendo irreversible aparecen nuevos tipos de problemas. En un caso, el de Turbaco, pueblo de indios, Antonio de la Torre actúa como despoblador, ya que expulsa a los blancos, mestizos y mulatos que residen allí ilegalmente; en otros, se enfrenta a los eclesiásticos que intentan imponerle el lugar donde deben situarse las nuevas poblaciones, "mirando más a su interés que al beneficio del públicon. Por fin, aprovecha su situación de fuerza y prestigio para colapsar la voluntad de los que se oponen a sus designios, quebrando toda forma de resistencia activa o pasiva. En el camino del Corozal, varios sujetos apostados se abstienen de atacarle "persuadiéndose que el mono que llevaba conmigo era algún demonio que me defendian. El estudio de una aguja de marear hace que le atribuyan aptitudes de mago, por lo que se difunde que no se le puede ocultar nada. En las ciénagas, donde los niños "se han acostumbrado por falta de tierra para caminar a hacerlo por los manglares imitando a los monos, caminando de rama en rama usando de los pies lo mismo que de las manos", una mujer experimenta ante su presencia tal turbación que da a luz de inmediato:

Al llegar con la barqueta al puerto del sitio de la Ciénaga 
corrió por él una voz diciendo "Blanco esta ahi" (que asi me solian nombrar), cuando una mujer embarazada que estaba barriendo, al oírlo, se le desataron las ligaduras que pone la naturaleza y dejó (asustada, sin dolor alguno, según dijo) caer una criatura a sus pies, felicidad que atribuyo al respeto que me tenia. La casa de ésta fue la única que quedo indultada por este accidente hasta que convaleciese.

Resulta evidente que el temor que produce su presencia y la fuerza militar son utilizados por Antonio de la Torre para imponerse definitivamente a quienes se oponen a sus designios. Esta actitud es muy significativa. Frente a políticos de frontera verdaderamente gradualistas, como Francisco de Requena, protagonista de un considerable esfuerzo de comprensión del mundo americano selvático y promotor de alianzas con los indígenas (25), nuestro personaje se limita a observar las equivocadas costumbres de los pobladores y se impone sin hacer concesiones. El caso de la información que aporta sobre las formas familiares es muy representativo. Históricamente, a pesar de la existencia de una patrilinealidad legal, las comunidades negras habían tendido a organizar sus relaciones sociales a partir de la matrilinealidad, con una sociedad centrada en la mujer donde "el ego de poder $y$ autoridad era ejercido por la gran madre con el mayor número de parentesco con [diversas] unidades familiares»(26). Incapaz de comprender peculiaridad cultural alguna, Antonio de la Torre señala:

Lo reducido de sus habitaciones manifiesta lo que puede ocurrir en un conjunto de padres, hermanos, hermanas, hijos y hijas [...] con cuyo motivo ignoran sus parentescos y castas y es tanta su idiotez que al formar el padrón ignoraban las madres los nombres de los hijos y algunas los de sus maridos y éstos con reciproca memoria [...] Se mezclan tan irracionalmente que no reservan las hijas, hermanas ni parientas y no dejan de usar de la poligamia con tanta serenidad de los parientes casados como si fuera de ley.

(25) Ver Manuel Lucena Giraldo, "La delimitación Hispano-Portuguesa y la frontera regional quiteña, 1777-1804", Procesos, Quito (en prensa). Requena elaboró una explicación racional a la antropofagia, criticó a quienes mantenían que el Amazonas era insalubre, ponderó la habilidad técnica de los indígenas, ete...

(26) Ver Mario Diego Romero, "Procesos de poblamiento y organización social en la costa pacífica colombiana", Anuario Colombiano de Historia Social y de la Cultura, no 18-19, Bogotá, Universidad Nacional, 1991, págs. 14 y ss. Aunque se refiere al Pacífico, creemos que las referencias resultan igualmente válidas en nuestro caso. 
A la vista de la información suministrada tanto por la Noticia Individual como por el Diario, es posible llegar a algunas conclusiones. En primer lugar, no creemos que se pueda seguir sosteniendo que las Nuevas Poblaciones cartageneras, al menos entre 1774 y febrero de 1776, obedecen al modelo de las Nuevas Poblaciones peninsulares. Quizás Antonio de la Torre conoció ya en esa etapa la Real Cédula de 1767 sobre la que se erigieron, pero en el Diario no hace mención alguna a ella. Por el contrario, lejos de modelos establecidos, muestra un empirismo radical. En el reparto de la tierra se comporta de manera absolutamente tradicional, limitándose a seguir las Leyes de Indias o a comportarse de manera aleatoria; en Arjona procura dar más terreno del que le habían pedido los vecinos a fin de que «lograsen tener dentro de su cerca todas las oficinas menesterosas de un labradon, pero en otra ocasión sufre un atentado a cargo de un vecino que no está conforme con el solar otorgado, que consideraba insuficiente. No hay alusión alguna a la creación de una sociedad rural modelo, relativamente igualitaria y con la acumulación de propiedad vedada, como en el caso peninsular. El proceso descrito por Antonio de la Torre en el Diario no es en modo alguno el de un proyecto poblacional, sino el de una concentración de habitantes dispersos en nuevos y viejos establecimientos apoyada, cuando fue necesario, en la fuerza mili$\operatorname{tar}(27)$.

Por otra parte, las alusiones de la Noticia Individual a la difusión de los textiles y la promoción del trabajo femenino como logros característicos del proceso poblacionista tampoco pueden ser aceptables para el período descrito en el Diario. En primer lugar, el paradigmático Discurso sobre el Fomento de la Industria Popular del Conde de Campomanes y las obras relacionadas con él no estaban aún a la disposición del público cuando

(27) Orlando Fals Borda, [8], ver T. III y IV, anota que Antonio de la Torre sentó las bases de la transformación económica regional en la provincia cartagenera al impulsar una especie de reforma agraria popular con la redistribución de la tierra, el señalamiento de ejidos a los pueblos, la disposición de caminos para impulsar la comunicación y el comercio, etc... Lo interesante de estas medidas es que formaban parte de una tradición bien consolidada, la de la legislación indiana, pero no de un discurso modernizador que en el siglo XIX impulsará las medidas opuestas. Así pues, paradójicamente, hoy aparece Antonio de la Torre como un progresista modernizador... cuando realmente se limitó a aplicar la legislación del siglo XVI. Cuando se opone a lo que él llama los magnates, representantes de poderosos intereses regionales, es fundamentalmente para imponer el poder del Estado, no para aplicar modelos igualitarios; ver Pilar MORENO DE ANGEL, [12], cap. 3 , págs. 48 y ss. 
Antonio de la Torre comenzó sus fundaciones (28). Resulta muy sintomático que en el Diario no haya alusión al trabajo textil femenino, aunque Antonio de la Torre anota que el cura de Pileta, Juan Antonio Aballe, para "evitar la ociosidad" había introducido por voluntad propia telares para fabricar lienzos de algodón.

Obviamente, resulta imposible saber si en años sucesivos Antonio de la Torre conoció las obras de Campomanes e intentó aplicar el modelo peninsular en el Sinú, el Darién o incluso en Cartagena, pero nos inclinamos por creer que fue a principios de la década de los ochenta, al relacionarse con el arzobispo-virrey Antonio Caballero y Góngora -que muestra una fuerte influencia de Campomanes en su ideología poblacionista- cuando verdaderamente recibió el influjo de sus ideas y desarrollo el modelo poblador que refleja, a posteriori, la Noticia Individual.

Esta afirmación también es convalidada por la inexistencia en las Nuevas Poblaciones cartageneras de una verdadera traza urbana y por los datos que emergen de los empadronamientos efectuados en 1784. No hay modelo urbano alguno; aparecen plantas organicistas - San José de Rocha, Santa Rosa de Francisco, Santa Rosa de Flamenco, San Francisco de Asís, Santero-, semiregulares - San Juan de Nepomuceno, San Luis de Since, San Onofre de Torobe- y en damero - San Pedro Apóstol de Pinchoroy, San José de Pileta, San Benito Abad-. Ni en calles ni en manzanas se sigue ley alguna, y las plazas varían, al igual que la posición del templo (29). Esta situación parece una consecuencia lógica tanto del reiteradamente mencionado empirismo del proceso poblacional como de la oficialización de núcleos urbanos previamente existentes. Aunque Ternera, Arjona, Pasacaballos, Santa Ana, San José de Rocha, San José de Jolojolo, Santa Rosa de Flamenco, Gambote, San Cayetano, San Juan Nepomuceno, San Jacinto, Nuestra Señora del Carmen, San Francisco de Asís, San Agustín de Playablanca y San José de Piletas son pueblos nuevos, el propio Antonio de la Torre habla de poblaciones nuevamente fundadas e indica haber establecido San Juan de Timiriguaco sobre un antiguo pueblo de indios, así como haber trasladado San Benito Abad y haber "reunido" las parroquias de

(28) [5] pág. 238. En septiembre de 1774 Campomanes manifestó que ya se hallaban encuadernados 30.000 ejemplares del Discurso sobre el fomento de la industria popular, que quedaban así listos para su distribución.

(29) Ver [22] pág. 223. En el mapa de 1778, citado en [23], Antonio de la Torre reprodujo una clásica planta en cuadrícula, que fue, en todo caso, el modelo seguido sólo en algunas de las Nuevas Poblaciones. 
Santa Cruz de Lorica, San Antonio de Momil y San Antonio de Ciénaga del Oro. Las Nuevas Poblaciones fueron, al menos en ciertos casos, más antiguas de lo que se ha supuesto.

Por otra parte, en 1784 se enviaron a Antonio de la Torre - nombrado por el arzobispo-virrey comisionado para asuntos de población - algunos padrones de las Nuevas Poblaciones cartageneras (30). Resulta llamativo que, ya en España, al preparar la publicación de la Noticia Individual para obtener sus recompensas Antonio de la Torre no empleara los datos de estos padrones, que recogían, hasta donde podemos hacer comparaciones, un número de pobladores relativamente menor del que indica la Noticia Individual de 1794, como se puede observar en el cuadro siguiente (31).

Es posible que el antiguo capitán poblador considerara que la reducción en el número de pobladores podía empeorar sus posibilidades de ser premiado, una pretensión en la que acabará por fracasar. En todo caso, era una licencia que, en un viejo y cumplidor soldado, podía ser vista con indulgencia. Mientras tanto, agotada ya la edad de las reformas, se abría paso el tiempo de las revoluciones; éstas no afectarían en nada los propósitos poblacionistas de los gobernantes del Nuevo Reino de

(30) Padrones de la Provincia de Cartagena de Indias (1784), AHNC, Milicias $v$ Marina, T. 141. El cometido de Antonio de la Torre en ese cargo parece haber sido preparar estados de la población del Nuevo Reino e identíficar individuos peligrosos y marginales, como fruto de la preocupación del arzobispo-virrey por el saneamiento del Virreinato, recientemente sacudido por la revolución comunera. Los causas para ser incluido en la lista de "sujetos viciados"fueron el amancebamiento, ser cizañeros, inobedientes a la justicia, "alcahuete de sus hijos", zenón, sin oficio, ebrio, vagabundo, ladrón, o de modo genérico "no cumplir con sus obligaciones".

(31) Ver [29]. Sabemos que hubo al menos dos empadronamientos, el de la etapa fundacional, de 1774 a 1778, y el de 1784. Es posible que los datos publicados en la Noticia Individual de 1794 provengan de los primeros y que, sencillamente, Antonio de la Torre no pudiera disponer de los padrones de 1784 en España. A pesar de la irregularidad de la información aportada por los padrones de 1784, es posible reseñar algunos datos cualitativos. El pueblo de San Francisco de Asís tenía 475 habitantes, agrupados en 63 familias nucleares con 261 hijos y 19 familias monoparentales con 69 hijos. San Cristóbal de Caracol tenia 320 habitantes en 65 grupos familiares, que contaban con 108 párvulos y 88 hijos "mayores de edad"; San Onofre de Torobe tenía 611 habitantes, con 144 vecinos; habia 94 familias nucleares con 285 hijos y 16 solteros, además de 29 viudas y 4 viudos que reunian 89 hijos. San Bernardo Abad tenía 1.267 habitantes agrupados en 169 grupos familiares, 112 familias nucleares con 336 hijos y 57 monoparentales con 137 hijos, 32 agregados y 8 esclavos, con un total de hijos mayor, 473. En San Pelayo había 1.301 habitantes en 318 grupos familiares, con 225 familias nucleares y 93 monoparentales con 147 hijos. Por fin, San Emigdio, con 845 habitantes, habla 240 grupos familiares en 161 familias nucleares y 79 monoparentales. 
NUEVAS POBLACIONES DE ('ARTAGENA (1784-1794)

\begin{tabular}{|c|c|c|}
\hline PUt:BLoS & PAIRONONS (17KA) & $\begin{array}{c}\text { NOTIC IA INIDIVIII) UAI. } \\
(1794)\end{array}$ \\
\hline S. Francisco de Asís & 475 & 448 \\
\hline Santiago de Tolú & 319 & 378 \\
\hline S. Cristóbal de Caracol & 320 & 325 \\
\hline S. Onofre de Torobe & 611 & 879 \\
\hline S. Antonio Abad & 616 & 677 \\
\hline S. Bernardo Abad & 1.267 & 1.368 \\
\hline Sta. Cruz de Lorica & 3.585 & 4.358 \\
\hline S. Pelayo & 1.301 & 1.475 \\
\hline S. Emigdio & 845 & 595 \\
\hline S. Carlos & 440 & 408 \\
\hline TOTAL & 9.779 & 10.911 \\
\hline
\end{tabular}

Granada. A fin de cuentas, como señaló sabiamente el arzobispovirrey Antonio Caballero y Góngora, eliminar las espinas de una planta era como trasladar a los malos habitantes del reino, trasplantar y podar como asentar las poblaciones en los lugares donde pudieran dar un fruto verdadero:

De iguales providencias y reconocimientos necesita todo el reino para ordenar su desarreglada población. Poco importaría trabajar con excesivos afanes aunque siempre bien empleados en cultivar la grosería y rudeza en que nacen, viven $y$ mueren sus miserables habitantes, si alguna vez no se pensara en dar principio a mejorar un terreno solamente dispuesto a producir espinas. El prelado y sus párrocos lograrán únicamente sembrar $y$ segar. Al gobierno pertenece arrancar y trasplantar. Mucho puede mejorarse la calidad del fruto con las continuas fatigas del obrero, pero nunca pierde sus resabios silvestres cualquiera planta nacida y alimentada en el campo (32).

(32) Carta de A. Caballero y Góngora a José de Gálve\%, Santa Fe, 15 de octubre de 1782, AGI, Santa Fe, 594. 